\title{
TINGKAT KEPENTINGAN RISIKO DAN RESPON RISIKO PADA TAHAP PELAKSANAAN PROYEK KONSTRUKSI
}

\author{
Anton Widjaja ${ }^{1}$, Andi $^{2}$, Paulus Nugraha ${ }^{3}$
}

\begin{abstract}
ABSTRAK : Frekuensi dan dampak bisa mewakili tingkat kepentingan risiko. Karena itu tingkat kepentingan risiko harus diketahui agar bisa mendapatkan prioritas risiko. Setelah itu respon risiko dilakukan pada masing-masing risiko menurut tingkat kepentingannya. Penelitian ini bertujuan untuk mencari tingkat kepentingan dan respon risiko pada masingmasing risiko yang diidentifikasi. Pengumpulan data dilakukan dengan menyebar kuesioner kepada owner, konsultan perencana, MK, dan kontraktor yang terlibat langsung di lapangan di wilayah Surabaya. Kemudian data dianalisa dengan uji t-test untuk frekuensi dan dampak risiko, sedangkan respon risiko diuji menggunakan uji chi-square. Hasil penelitian menunjukan bahwa pada tingkat kepentingan risiko ditemukan bahwa risiko internal baik masing-masing owner dan kontraktor lebih cenderung pada tingkat kepentingan extreme dan high, sedangkan risiko eksternal lebih cenderung pada tingkat kepentingan medium dan low. Dengan frekuensi dengan mean tertinggi dan dampak dengan mean tertinggi menurut owner adalah kekurangan pekerja sedangkan pada kontraktor adalah permintaan change order oleh owner, diikuti beberapa perbedaan pendapat untuk frekuensi dan dampak. Kemudian ditemukan bahwa strategi untuk merespon risiko menurut tingkat kepentingan extreme dan high adalah dengan menghindari dan mengurangi, sedangkan pada tingkat kepentingan medium dan low adalah dengan menghindari dan menerima, dengan adanya beberapa perbedaan pendapat untuk merespon risiko.
\end{abstract}

Kata kunci: risiko, tingkat kepentingan risiko, respon risiko

ABSTRACT : Each risk has its own frequency and impact. Therefore the importance level of risk must be known to be prioritized. After that, the risk response is applied to each risk according to risk importance level. This paper aims to find the risk importance level and risk response to each of the risks concerned. The research method is by distributing questionnaires to the owner, consultant planner, construction management, and contractor who involved directly on project site in Surabaya area. Collected data will be analyzed using t-test for frequency and impact of risk, while the risk response will be analyzed using chisquare test. The result of the research discovers that the most frequency and impact according to owner's perspective is labor shortage while contractor's perspective stated change order by the owner has the most frequency and impact, followed with some dissent for frequency and impact. At risk importance level discovers that internal risk of both owner's and contractor's tend at high importance level. Then at the risk response stage also found some dissent between owner and contractor, actual response and expected response based on literature give almost the same result in this research. But there are some condition that must be added because the risk response depends on who is responsible for the risk.

Keywords : risk, risk importance level, risk response

\footnotetext{
${ }^{1}$ Mahasiswa Program Studi Magister Teknik Sipil Universitas Kristen Petra, m01515006@john.petra.ac.id ${ }^{2}$ Dosen Program Studi Magister Teknik Sipil Universitas Kristen Petra, andi@peter.petra.ac.id

${ }_{3}$ Dosen Program Studi Magister Teknik Sipil Universitas Kristen Petra, pnugraha@peter.petra.ac.id
} 


\section{PENDAHULUAN}

Proyek konstruksi adalah unik karena tidak ada proyek yang sama dengan proyek yang lainnya, dan juga kompleks dimana didalamnya memiliki banyak risiko dan ketidakpastian. Risiko dan ketidakpastian ini disebabkan oleh banyaknya sumber daya yang terlibat baik sumber daya alam maupun manusia, dan mesin. Dalam menentukan risiko mana yang paling penting, cara yang dapat digunakan adalah dengan menentukan tingkat kepentingan risiko.

Tingkat kepentingan risiko didapatkan dengan menggabungkan frekuensi kejadian dan dampak risiko. Dan untuk mengetahui tindakan lebih lanjut untuk risiko maka diperlukan respon risiko. Penelitian ini akan memfokuskan pada tingkat kepentingan risiko dan respon risiko. Penelitian ini terlebih dahulu mengumpulkan data frekuensi kejadian dan dampak risiko yang berpengaruh terhadap waktu pelaksanaan proyek melalui kuesioner. Data yang didapat kemudian diolah menjadi tingkat kepentingan risiko. Kemudian respon risiko yang belum pernah dibahas pada penelitian sebelumnya akan dilakukan pada penelitian ini.

\section{TINJAUAN PUSTAKA}

\subsection{Pengertian Proyek}

Menurut PMI (2013) proyek adalah usaha yang sifatnya sementara untuk menghasilan suatu produk dan atau jasa yang unik dan gabungan dari berbagai sumber daya dan serangkaian kegiatan yang dihimpun dalam suatu organisasi untuk mencapai tujuan tertentu. Setiap proyek selalu memiliki siklus yang disebut sebagai siklus kegiatan proyek (Project life cycle). Pada proyek dengan skala besar akan melibatkan banyak pihak sehingga biasanya owner akan menunjuk seseorang yang memiliki pengalaman yang sesuai untuk bertindak sebagai perwakilannya. Perwakilan owner adalah sebagai arsitek, project manager, dan konsultan (Nesan \& Price, 1997).

\subsection{Pengertian Risiko}

Risiko adalah insiden yang tidak diketahui atau keadaan yang, apabila itu terjadi maka dapat memiliki efek menguntungkan atau tidak menguntungkan pada tujuan proyek, dimana efek positif disebut opportunity sedangkan efek negatif disebut threat (PMI, 2013). Flanagan \& Norman (1993) mengungkapkan bahwa sumber dari risiko dan efek dari risiko harus dengan jelas dibedakan. Unsur pertama yaitu source (sumber), yang memiliki event (kejadian) dan effect (dampak). Keterlambatan waktu penyelesaian proyek merupakan salah satu dampak yang diakibatkan oleh risiko yang timbul pada proyek konstruksi.

\subsection{Risiko dan Penanganannya pada Proyek Konstruksi}

Manajemen risiko didefinisikan sebagai semua tindakan dan kegiatan yang dilakukan untuk mengelola risiko, yang mencakup semua jenis risiko dan berhubungan dengan semua kegiatan, kondisi, peristiwa yang dapat mempengaruhi kemampuan organisasi untuk mencapai tujuan (Kloman, 1990). Flanagan \& Norman (1993) membagi manajemen risiko menjadi empat tahap yaitu identifikasi, klasifikasi, analisa, dan respon risiko.

\subsubsection{Identifikasi dan Klasifikasi Risiko}

Identifikasi risiko adalah tahap pertama dalam manajemen risiko dimana pada tahap ini semua potensi risiko yang mungkin terjadi harus bisa dituliskan, dan proses ini sifatnya berulang karena risiko-risiko baru bisa muncul selama proses pembangunan berlangsung (PMI, 2013). Aleshin (2001) menyatakan bahwa risiko proyek dibagi menjadi dua kelompok menurut sumbernya, yaitu risiko internal dan eksternal. Pada penelitian ini dalam mengidentifikasi risiko dilakukan dengan cara menggunakan risiko dari penelitian serupa yang sudah pernah dilakukan berdasarkan para ahli yang tertulis pada jurnal, diantaranya adalah Kartam (2001), El-Sayegh (2008), Proboyo (1999), dan Gunduz et al. (2013). Dalam buku PMI (2013) metode ini disebut dengan checklist dimana identifikasi risiko dilakukan berdasarkan informasi historis dan pengalaman yang telah diakumulasikan dari proyek sebelumnya. 


\subsubsection{Analisa Risiko}

PMI (2013) menyebutkan bahwa tujuan analisa risiko secara kualitatif adalah metode untuk melakukan prioritas terhadap risiko yang telah diidentifikas. Manfaat dari proses ini adalah bisa mengetahui risiko dengan tingkat kepentingan yang rendah dan tinggi. Pada penelitian ini kriteria penilaian tingkat kepentingan risiko adalah berdasarkan pada Australian/New Zealand Standard Risk Management (AS/NZS 4360) yang ditunjukan pada Tabel 1.

Tabel 1. Matriks Risiko Kualitatif (AS/NZS 4360:2004 Risk Management)

\begin{tabular}{|l|c|c|c|c|c|}
\hline \multirow{2}{*}{$\begin{array}{c}\text { Frekuensi } \\
\text { Kejadian }\end{array}$} & \multicolumn{5}{|c|}{ Dampak terhadap Waktu } \\
\cline { 2 - 6 } & Sangat Kecil & Kecil & Sedang & Besar & $\begin{array}{c}\text { Sangat } \\
\text { Besar }\end{array}$ \\
\hline Sangat Sering & $\mathrm{H}$ & $\mathrm{H}$ & $\mathrm{E}$ & $\mathrm{E}$ & $\mathrm{E}$ \\
\hline Sering & $\mathrm{M}$ & $\mathrm{H}$ & $\mathrm{H}$ & $\mathrm{E}$ & $\mathrm{E}$ \\
\hline Kadang & $\mathrm{L}$ & $\mathrm{M}$ & $\mathrm{H}$ & $\mathrm{E}$ & $\mathrm{E}$ \\
\hline Jarang & $\mathrm{L}$ & $\mathrm{L}$ & $\mathrm{M}$ & $\mathrm{H}$ & $\mathrm{E}$ \\
\hline Sangat Jarang & $\mathrm{L}$ & $\mathrm{L}$ & $\mathrm{M}$ & $\mathrm{H}$ & $\mathrm{H}$ \\
\hline
\end{tabular}

Keterangan :

$\mathrm{L}$ : Low Risk, risiko rutin, ada pada anggaran pelaksanaan proyek

M : Moderate Risk, risiko rutin, ditangani langsung di lapangan

$\mathrm{H}$ : Significant Risk, perlu ditangani manajer proyek

$\mathrm{E}$ : Extreme Risk, perlu pengamatan rinci, penanganan level pimpinan

\subsubsection{Penanganan Risiko}

Penanganan risiko pada penelitian ini adalah sama dengan respon risiko. Tahap ketiga pada manajemen risiko ini menunjukkan tindakan apa yang harus diambil terhadap risiko yang sudah dianalisa tingkat kepentingannya. Respon risiko menjadi tahap yang paling penting pada tahapan manajemen risiko, karena memberikan respon mengenai risiko yang sudah diidentifikasi pada tahap sebelumnya (Zhi, 1995). Dalam buku PMI (2013) ada empat tindakan untuk merespon risiko yang sudah teridentifikasi.

\subsubsection{Strategi Avoid (Menghindari)}

Menghindari risiko adalah strategi respon risiko dimana tim proyek bertindak untuk menghilangkan ancaman tersebut atau melindungi proyek dari dampak risiko. Menghindari risiko bisa dilakukan dengan cara melakukan perubahan terhadap rencana manajemen proyek untuk mengeliminasi ancaman risiko, mengisolasi sasaran proyek dari dampak yang akan timbul, seperti mengurangi scope pekerjaan atau memperpanjang waktu pekerjaan. Menurut Flanagan \& Norman (1993) menghindari risiko dalam hal ini adalah sama dengan menolak untuk menerima risiko.

\subsubsection{Strategi Transfer (Mengalihkan)}

Mengalihkan risiko berarti harus ada pihak lain yang bersedia untuk bertanggung jawab jika risiko tersebut terjadi. Mengalihkan risiko bukan berarti menghilangkan risiko, ini berarti risiko dilimpahkan kepada pihak lain dengan persetujuan bersama (Flanagan \& Norman, 1993).

\subsubsection{Strategi Mitigate (Mengurangi)}

Mitigasi risiko adalah strategi respon risiko dimana tim proyek bertindak untuk mengurangi kemungkinan terjadinya atau dampak dari risiko. Mengambil tindakan untuk mencegah lebih baik daripada memperbaiki dampak yang terjadi apabila risiko tersebut sudah terjadi. Langkah-langkah mitigasi dilakukan dengan mengambil metode pekerjaan yang semudah mungkin, melakukan lebih banyak tes untuk hal-hal yang tidak pasti seperti tes tanah, tes kekuatan beton, dan lain-lain. 


\subsubsection{Strategi Accept (Menerima)}

Menerima risiko merupakan strategi respon risiko yang dipilih karena sangat kecil kemungkinannya untuk menghilangkan seluruh risiko dari sebuah proyek. Pada kasus ini menerima bukan berarti tidak melakukan apa-apa dan juga bukan pasrah namun lebih dengan menyiapkan suatu kontingensi yang bisa berupa waktu, uang, ataupun sumberdaya untuk menangani risiko.

\section{METODOLOGI PENELITIAN}

\subsection{Studi Literatur}

Pada penelitian ini sumber studi literatur dilakukan dengan mencari buku dan jurnal yang serupa, sehingga data-data yang didapatkan dapat dijadikan dasar penelitian. Pada bagian ini dijelaskan mengenai tahapan apa saja yang ada pada proyek konstruksi, dan pada bagaimana risiko proyek mempengaruhi pada setiap tahap tersebut.

\subsection{Penentuan Sampel}

Pada analisa data akan dikelompokan menjadi dua kelompok yaitu :

- Kelompok pertama adalah owner dan representatifnya yang terdiri dari owner, konsultan perencana, dan konsultan pengawas (MK).

- Kelompok kedua adalah kontraktor yang terdiri dari kontraktor saja.

Hal ini dilakukan karena konsultan perencana dan konsultan pengawas/manajemen konstruksi (MK) diberi tugas oleh owner dan menjadi perwakilan owner untuk mengawasi pekerjaan kontraktor.

\subsection{Pembuatan Kuesioner}

Penelitian ini menggunakan kuesioner tertutup dimana kuesioner sudah dibuat sedemikian rupa sehingga responden hanya memilih alternatif jawaban yang telah disediakan. Pengelompokan risiko menurut sumbernya (risiko internal dan eksternal) yang sudah dijelaskan pada Bab 2, pada kuesioner sengaja dihilangkan agar menghadirkan suasana netral pada kuesioner sehingga jawaban diharapkan tidak berpihak kepada diri sendiri.

\subsection{Analisa Mean Frekuensi Kejadian dan Dampak Risiko}

Hasil pengumpulan data melalui kuesioner dengan skala "Frekuensi Kejadian" dan "Dampak Risiko" maka data tersebut dirata - rata atau dihitung meannya. Metode analisa mean dihitung sebagai berikut:

$$
\begin{array}{lll} 
& M e=\frac{\sum_{i=1}^{n} X i}{n} \\
\mathrm{Me} & =\text { Nilai rata }- \text { rata (mean) } & \\
\mathrm{n} & =\text { Jumlah responden } & \\
\mathrm{Xi} & =\text { Data ke- } \mathrm{i} & \\
\sum X i & =\text { Jumlah keseluruhan data } &
\end{array}
$$

\subsection{Analisa Perbedaan Frekuensi Kejadian dan Dampak Risiko Antara Owner dan Kontraktor}

Untuk mencari perbedaan pendapat frekuensi kejadian antar responden digunakan uji dua sampel bebas yang tidak saling berhubungan (t-test). Uji $t$-test merupakan uji beda untuk mengetahui adakah perbedaan mean yang berbeda antara 2 kelompok bebas (independent). Uji ini dilakukan dengan menggunakan bantuan program IBM Statistik SPSS v.23.

3.6 Analisa Perbedaan Pendapat Respon Risiko Antara Owner dan Kontraktor Untuk mengetahui perbedaan pendapat responden dalam menganalisa risiko maka digunakan uji Chi Square $\left(\mathrm{x}^{2}\right)$. Uji Chi Square digunakan karena skala data variabel adalah nominal. Uji ini dilakukan dengan menggunakan bantuan program IBM Statistik SPSS v.23. 


\section{ANALISA DATA DAN PEMBAHASAN}

\subsection{Analisa Deskriptif Frekuensi Kejadian}

Pada Tabel 2 dapat dilihat bahwa menurut owner risiko kekurangan pekerja merupakan risiko yang sering muncul. Kekurangan pekerja ini bisa disebabkan karena kesalahan kontraktor dalam merencanakan alokasi tenaga kerja. Owner dan kontraktor juga berpendapat bahwa change order memang sering terjadi. Penelitian Andi (2006) juga menyebutkan bahwa change order adalah risiko yang paling sering terjadi menurut pandangan owner dan kontraktor.

Tabel 2. Mean Frekuensi Kejadian Tertinggi menurut Owner dan Kontraktor

\begin{tabular}{|c|c|c|}
\hline Rank & Owner & Kontraktor \\
\hline 1 & Kekurangan pekerja & Permintaan change order oleh owner \\
\hline 2 & $\begin{array}{l}\text { Kurangnya koordinasi kontraktor dengan } \\
\text { supplier dan subkontraktor }\end{array}$ & $\begin{array}{l}\text { Perubahan desain/detail pekerjaan oleh } \\
\text { perencana }\end{array}$ \\
\hline 3 & $\begin{array}{l}\text { Penjadwalan proyek tidak terencana dengan } \\
\text { baik }\end{array}$ & $\begin{array}{l}\text { Kondisi cuaca yang tidak menentu (hujan, } \\
\text { badai, dIII) }\end{array}$ \\
\hline 4 & Permintaan change order oleh owner & $\begin{array}{l}\text { Lambat dalam mereview dan menyetujui } \\
\text { shopdrawing }\end{array}$ \\
\hline 5 & $\begin{array}{l}\text { Kurangnya koordinasi perencana dengan } \\
\text { kontraktor }\end{array}$ & Kekurangan pekerja \\
\hline
\end{tabular}

\subsection{Analisa Deskriptif Dampak Risiko}

Pada Tabel 3. Dapat dilihat bahwa kekurangan pekerja membawa dampak paling besar pada penyelesaian proyek menurut owner. Gunduz (2013) menambahkan bahwa kualitas dan pengalaman pekerja dapat memberi dampak pada proyek. Pekerja yang tidak berpengalaman terutama dapat menyebabkan pekerjaan terlambat. Kontraktor mengungkapkan dampak keterlambatan proyek tertinggi yaitu permintaan change order oleh owner. Change order seharusnya tidak boleh mengganggu pelaksanaan secara signifikan.

Tabel 3. Mean Dampak Risiko Tertinggi menurut Owner dan Kontraktor

\begin{tabular}{cll}
\hline Rank & \multicolumn{1}{c}{ Owner } & \multicolumn{1}{c}{ Kontraktor } \\
\hline 1 & $\begin{array}{l}\text { Kekurangan pekerja } \\
\text { Pekerjaan ulang karena tidak sesuai } \\
\text { gambar/buruk }\end{array}$ & $\begin{array}{l}\text { Permintaan change order oleh owner } \\
\text { Perubahan desain/detail pekerjaan oleh } \\
\text { perencana }\end{array}$ \\
3 & $\begin{array}{l}\text { Keuangan internal kontraktor tidak } \\
\text { terencana dengan baik tidak terencana } \\
\text { Kekurangan pekerja } \\
\text { Lenjadwalan proyek tidat dalam mereview dan menyetujui } \\
\text { dengan baik }\end{array} \quad \begin{array}{l}\text { shopdrawing } \\
\text { Perencana yang kurang berpengalaman }\end{array}$ \\
\hline
\end{tabular}

\subsection{Analisa Perbedaan Pendapat Frekuensi Kejadian antara Owner dan Kontraktor} Pada Tabel 4. dapat dilihat perbedaan pendapat signifikan untuk frekuensi kejadian.Terdapat perbedaan pendapat pada frekuensi kejadian untuk lambatnya pengambilan keputusan oleh owner antara owner dan kontraktor dengan mean 3,33 (owner) > 2,95 (kontraktor) dan pada frekuensi kejadian keuangan internal kontraktor yang tidak terencana dengan baik antara owner dan kontraktor dengan mean 2,73 (owner) > 2,23 (kontraktor). Pada frekuensi kejadian, pihak owner lebih sering berpendapat bahwa frekuensi kejdaian yang berbeda signifikan adalah lebih tinggi dibandingkan dengan pendapat kontraktor. 
Tabel 4. Perbedaan Pendapat Frekuensi Kejadian antara Owner dan Kontraktor

\begin{tabular}{clcc}
\hline \multirow{2}{*}{ No. } & \multicolumn{1}{c}{ Jenis Risiko } & \multicolumn{2}{c}{ Signifikansi } \\
\cline { 3 - 4 } & & Sig. (2-tailed) & Kesimpulan \\
\hline 3 & Lambatnya pengambilan keputusan oleh owner & $0,034^{*}$ & Ada perbedaan \\
14 & Keuangan internal kontraktor tidak terencana dengan baik & $0,008^{*}$ & Ada perbedaan \\
15 & Kurangnya koordinasi kontraktor dengan supplier dan & $0,014^{*}$ & Ada perbedaan \\
16 & subkontraktor & $0,001^{*}$ & Ada perbedaan \\
17 & Penjadwalan proyek tidak terencana dengan baik & $0,002^{*}$ & Ada perbedaan \\
20 & Produktifitas pekerja yang rendah & $0,032^{*}$ & Ada perbedaan \\
31 & Klaim masyarakat sekitar proyek & $0,006^{*}$ & Ada perbedaan \\
\hline${ }^{*}$ Siginifikan pada $p<0,05$ & &
\end{tabular}

\subsection{Analisa Perbedaan Pendapat Dampak Risiko antara Owner dan Kontraktor}

Pada Tabel 4. Dapat dilihat perbedaan pendapat signifikan untuk dampak risiko. Pada dampak risiko terjadi kecelakaan kerja antara owner dan kontraktor dengan mean 2,47 (owner) <2,67 (kontraktor) merupakan perbedaan dimana dampak yang dirasakan kontraktor lebih besar dibandingkan owner. Sedangkan pada risiko lainnya berdasarkan pendapat owner, dampak yang dirasakan oleh owner lebih besar dibandingkan dengan kontraktor.

Tabel 4. Perbedaan Pendapat Dampak Risiko antara Owner dan Kontraktor

\begin{tabular}{clcc}
\hline \multirow{2}{*}{ No. } & \multicolumn{2}{|c}{ Jenis Risiko } & \multicolumn{2}{c}{ Signifikansi } \\
\cline { 3 - 4 } & & Sig. (2-tailed) & Kesimpulan \\
\hline 13 & Lambat dalam mereview dan menyetujui shopdrawing & $0,016^{*}$ & Ada perbedaan \\
14 & Keuangan internal kontraktor tidak terencana dengan baik & $0,000^{*}$ & Ada perbedaan \\
20 & Produktifitas pekerja yang rendah & $0,001^{*}$ & Ada perbedaan \\
26 & Pekerjaan ulang karena tidak sesuai gambar/buruk & $0,020^{*}$ & Ada perbedaan \\
27 & Terjadi kecelakaan kerja & $0,019^{*}$ & Ada perbedaan \\
\hline
\end{tabular}

${ }^{*}$ Siginifikan pada $p<0,05$

\subsection{Analisa Tingkat Kepentingan Risiko dan Respon Risiko}

Pada Tabel 5. Dapat dilihat bahwa tingkat kepentingan risiko ekstrim lebih banyak dibandingkan tingkat kepentingan lain. Yang berbeda pada penelitian ini adalah dimana tingkat risiko untuk kondisi cuaca yang tidak menentu termasuk dalam tingkat ekstrim sedangkan pada jurnal Kartam (2001) mengungkapkan bahwa kondisi cuaca termasuk tingkat kepentingan risiko rendah. Pada tingkat kepentingan extereme dan high diisi dengan risiko internal.

Tabel 5. Tingkat Kepentingan Risiko dan Respon Risiko antara Owner dan Kontraktor

\begin{tabular}{lllcccc}
\hline \multirow{2}{*}{ No. } & & \multicolumn{2}{c}{ Jenis Resiko } & \multicolumn{2}{c}{ Kontraktor } \\
\cline { 3 - 6 } & & T. & Respon & T.K & Respon \\
\hline 1 & Lambatnya pembayaran owner kepada kontraktor & E & Mengurangi & E & Menghindari \\
2 & Permintaan change order oleh owner & E & Mengurangi & E & Mengurangi \\
3 & Lambatnya pengambilan keputusan oleh owner & E & Mengurangi & E & Mengalihkan \\
4 & Penetapan jadwal proyek yang amat ketat oleh owner & H & Mengurangi & H & Menerima \\
5 & Pembagian scope pekerjaan yang tidak jelas oleh owner & H & Mengurangi & E & Mengalihkan \\
6 & Lokasi proyek yang sulit dijangkau & M & Mengurangi & H & Menghindari \\
7 & Perencanaan gambar/spesifikasi yang salah/tidak lengkap & E & Menghindari & E & Mengalihkan
\end{tabular}


Tabel 5. Tingkat Kepentingan Risiko dan Respon Risiko antara Owner dan Kontraktor (sambungan)

\begin{tabular}{|c|c|c|c|c|c|}
\hline \multirow[t]{2}{*}{ No } & \multirow[t]{2}{*}{ Jenis Resiko } & \multicolumn{2}{|r|}{ Owner } & \multicolumn{2}{|c|}{ Kontraktor } \\
\hline & & $\begin{array}{l}\text { T. } \\
\text { K }\end{array}$ & Respon & T.K & Respon \\
\hline 8 & Perubahan desain/detail pekerjaan oleh perencana & E & Mengalihkan & $E$ & Mengalihkan \\
\hline 9 & Gambar tidak dikeluarkan tepat waktu oleh perencana & $\mathrm{H}$ & Mengurangi & $E$ & Mengalihkan \\
\hline 10 & Perencana yang kurang berpengalaman & $\mathrm{H}$ & Menghindari & $E$ & Menghindari \\
\hline 11 & Kurangnya koordinasi perencana dengan kontraktor & $\mathrm{E}$ & Menghindari & $E$ & Mengalihkan \\
\hline 12 & Desain bangunan yang kompleks/sulit dikerjakan & $\mathrm{E}$ & Mengurangi & E & Mengurangi \\
\hline 13 & Lambat dalam mereview dan menyetujui shopdrawing & $E$ & Mengurangi & E & Mengalihkan \\
\hline 14 & Keuangan internal kontraktor tidak terencana dengan baik & $E$ & Menghindari & $\mathrm{H}$ & Mengurangi \\
\hline 15 & $\begin{array}{l}\text { Kurangnya koordinasi kontraktor dengan supplier dan } \\
\text { subkontraktor }\end{array}$ & $\mathrm{E}$ & Mengalihkan & $E$ & Mengurangi \\
\hline 16 & Tim proyek yang kurang kompeten/ kurang pengalaman & $\mathrm{E}$ & Mengurangi & $\mathrm{H}$ & Mengurangi \\
\hline 17 & Penjadwalan proyek tidak terencana dengan baik & $E$ & Mengurangi & $E$ & Mengurangi \\
\hline 18 & Metode kerja yang salah atau tidak tepat & $\mathrm{E}$ & Menghindari & $E$ & Mengurangi \\
\hline 19 & Kekurangan pekerja & $E$ & Menghindari & E & Mengurangi \\
\hline 20 & Produktifitas pekerja yang rendah & $E$ & Menghindari & $\mathrm{H}$ & Mengurangi \\
\hline 21 & Ketersediaan material di lapangan & E & Mengalihkan & $E$ & Mengalihkan \\
\hline 22 & Material yang datang rusak atau tidak sesuai & $\mathrm{H}$ & Menghindari & M & Mengalihkan \\
\hline 23 & Keterlambatan pengiriman material & $E$ & Mengalihkan & $E$ & Mengalihkan \\
\hline 24 & Produktifitas alat yang rendah (tidak memadahi) & $\mathrm{H}$ & Mengalihkan & M & Mengalihkan \\
\hline 25 & Kerusakan peralatan & $\mathrm{H}$ & Mengalihkan & $\mathrm{H}$ & Mengurangi \\
\hline 26 & Pekerjaan ulang karena tidak sesuai gambar/buruk & E & Menghindari & E & Mengurangi \\
\hline 27 & Terjadi kecelakaan kerja & $\mathrm{L}$ & Mengalihkan & M & Mengurangi \\
\hline 28 & Adanya perubahan hukum dan peraturan oleh pemerintah & M & Menerima & $L$ & Menerima \\
\hline 29 & Lambatnya pengadaan utilitas dari pemerintah (air,listrik) & M & Menerima & M & Mengalihkan \\
\hline 30 & Terjadinya demo/kerusuhan & $\mathrm{L}$ & Menerima & $\mathrm{L}$ & Menerima \\
\hline 31 & Klaim masyarakat sekitar proyek & $\mathrm{H}$ & Mengurangi & $\mathrm{H}$ & Mengalihkan \\
\hline 32 & Kondisi lapangan tidak sesuai dengan survei awal & E & Mengalihkan & $E$ & Mengalihkan \\
\hline 33 & Kondisi cuaca yang tidak menentu (hujan, badai, dII) & E & Menerima & E & Mengurangi \\
\hline 34 & Force majeure (gempa bumi, banjir, tanah longsor, dll) & M & Mengalihkan & M & Mengalihkan \\
\hline
\end{tabular}

Jika melihat dari sumber risiko maka masing-masing owner dan kontraktor lebih cenderung untuk memilih strategi mengurangi. Hal ini berarti kedua pihak merasa risiko yang berada pada pihak mereka masing-masing masih dalam penanganan sehingga frekuensi dan dampak risiko bisa diminimalkan. Contohnya owner akan berusaha untuk mengurangi lambatnya pembayaran ke kontraktor agar dapat diteruskan ke supplier. Pada risiko change order, respon yang diberikan owner maupun kontraktor adalah dengan mengurangi, karena akan berdampak pada waktu pelaksanaan. Untuk risiko yang berhubungan dengan material, kontraktor memilih strategi mengalihkan dimana berarti kontraktor akan melimpahkan jika ada terjadi kerusakan, keterlambatan pengiriman, dan ketersediaan material kepada pihak supplier. Untuk respon risiko menerima jika dilihat dari tingkat kepentingannya maka rata-rata berada pada tingkat kepentingan rendah, kecuali pada risiko cuaca yang tidak menentu 


\subsection{Analisa Perbedaan Pendapat Respon Risiko antara Owner dan Kontraktor} Terdapat perbedaan pendapat yang signifikan antara respon risiko lambatnya pembayaran owner kepada kontraktor yang bisa dilihat pada Tabel 6. Perbedaan paling signifikan adalah koordinasi kontraktor dengan supplier dan subkontraktor, owner memilih strategi mengalihkan sedangkan kontraktor memilih strategi mengurangi. Koordinasi dan komunikasi merupakan hal yang penting karena banyaknya pihak yang terlibat (Gunduz, 2013). Sehingga kontraktor harus mengurangi dampak risiko dengan cara lebih sering berkomunikasi dengan supplier dan subkontraktor. Sedangkan owner akan mengalihkan risiko ini kepada kontraktor karena owner tidak ingin terlibat pada urusan kontraktor lebih dalam. Sedangkan kekurangan pekerja owner memilih mengalihkan sementara kontraktor memilih mengurangi. Hal ini karena owner selalu ingin pekerja di lapangan sesuai dengan kebutuhan jika kekurangan pekerja maka owner akan mengalihkan dengan mengundang subkontraktor lain.

Tabel 6. Perbedaan Pendapat Respon Risiko antara Owner dan Kontraktor

\begin{tabular}{clcc}
\hline \multirow{2}{*}{ No. } & \multicolumn{1}{c}{ Jenis Risiko } & \multicolumn{2}{c}{ Respon } \\
\cline { 3 - 4 } & & Sig (2-tailed) & Kesimpulan \\
\hline 1 & Lambatnya pembayaran owner kepada kontraktor & $0,003^{*}$ & Ada perbedaan \\
4 & Penetapan jadwal proyek yang amat ketat oleh owner & $0,020^{*}$ & Ada perbedaan \\
5 & Pembagian scope pekerjaan yang tidak jelas oleh owner & $0,042^{*}$ & Ada perbedaan \\
11 & Kurangnya koordinasi perencana dengan kontraktor & $0,000^{*}$ & Ada perbedaan \\
\cline { 3 - 5 } & Tabel 6. Perbedaan Pendapat Respon Risiko antara Owner dan Kontraktor (Sambungan) \\
\hline \multirow{2}{*}{ No. } & \multicolumn{2}{c}{ Jenis Risiko } & \multicolumn{2}{c}{ Respon } \\
\cline { 3 - 5 } & & Sig (2-tailed) & Kesimpulan \\
\hline 14 & Keuangan internal kontraktor tidak terencana dengan baik & $0,029^{*}$ & Ada perbedaan \\
15 & Kurangnya koordinasi kontraktor dengan supplier dan & $0,011^{*}$ & Ada perbedaan \\
19 & Kubkontraktor & $0,000^{*}$ & Ada perbedaan \\
20 & Produktifitas pekerja yang rendah & $0,001^{*}$ & Ada perbedaan \\
26 & Pekerjaan ulang karena tidak sesuai gambar/buruk & $0,001^{*}$ & Ada perbedaan \\
27 & Terjadi kecelakaan kerja & $0,001^{*}$ & Ada perbedaan \\
\hline${ }^{*}$ Siginifikan pada $p<0,05$ & \multicolumn{3}{c}{}
\end{tabular}

\section{KESIMPULAN}

Secara umum owner dan kontraktor sepakat bahwa sumber risiko internal yaitu owner dan kontraktor rata-rata adalah risiko dengan tingkat kepentingan extreme dan high. Sedangkan pada risiko eksternal, owner dan kontraktor sepakat bahwa rata-rata memiliki tingkat kepentingan medium dan low. Sedangkan frekuensi dan dampak terhadap waktu pelaksanaan dengan mean tertinggi menurut owner adalah kekurangan pekerja, sedangkan kontraktor adalah permintaan change order dari owner.

Melihat dari tingkat kepentingannya, owner dan kontraktor mengemukakan bahwa pada tingkat kepentingan extreme dan high direspon dengan strategi menghindari atau mengurangi sedangkan risiko dengan tingkat kepentingan medium dan low direspon dengan strategi mengalihkan dan menerima. Sedangkan apabila berdasarkan sumber risikonya pada risiko internal, owner dan kontraktor merespon dengan strategi menghindari atau mengurangi. Namun pada risiko internal terdapat banyak perbedaan pendapat yang signifikan untuk merespon risiko. Sedangkan pada risiko eksternal direspon dengan strategi mengalihkan dan menerima, dan tidak ada perbedaan pendapat yang signifikan untuk respon risiko. 


\section{DAFTAR REFERENSI}

Project Management Institute (2013). "A Guide to the Project Management Body of Knowledge" PMBOK Guide, 3rd ed. PMI, Inc. Newtown Square, PA.

Aleshin, A. (2001). "Risk Management of International Projects in Russia." International Journal of Project Management, 19(4), 207-222.

Committee, Australia/New Zealand Standard. (2004). AS/NZS 4360:2004 Risk Management, from www.riskmanagement.com.au/

El-Sayegh, S. (2008). "Risk Management and Allocation in The UAE Construction Industry." International Journal of Project Management, 26(4), 431-438.

Flanagan, R. \& Norman, G. (1993). Risk Management and Construction, Blackwell Scientific Publication. Oxford

Gunduz, M. Nielsen, Y., \& Ozdemir, M., (2013). "Quantification of Delay Factors Using the Relative Importance Index Method for Construction Projects in Turkey," Journal of Management in Engineering, 29(2), 133-139.

Kartam, N., \& Kartam, S. (2001). "Risk and Its Management in The Kuwaiti Construction Industry: A Contractors' Perspective.” International Journal of Project Management, 19(6), 325-335.

Kloman, H.F. (1990) “Risk Management Agonistes.” Journal of Risk Analysis, 10 (2), 201-205.

Nesan, L. J., Price, A.D.F., (1997). "Formulation of Best Practices for Owner's Representatives." Journal of Management in Engineering, 13(1). 44-51.

Proboyo, B. (1999), "Keterlambatan Waktu Pelaksanaan Proyek: Klasifikasi dan Peringkat dari Penyebab-Penyebabnya," Dimensi Teknik Sipil, 1(2), 1999

Zhi, H. (1995). "Risk Management for Overseas Construction Projects." International Journal of Project Management, 13(4), 231-237. 